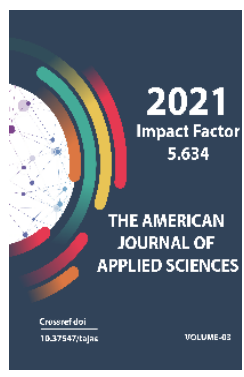

\title{
Criteria For Assessing The Efficiency Of Laboratory Works
}

Mukhammad Makhmudovich Yusupov

Teacher, Physics And Technology Faculty, Jizzakh State Pedagogical Institute, Uzbekistan

Journal Website:

http://usajournalshub.c

om/index,php/tajas

Copyright: Original

content from this work

may be used under the

terms of the creative

commons attributes

4.0 licence.

\section{ABSTRACT}

This article discusses the problem of criteria for assessing the effectiveness of laboratory work. To assess the effectiveness of laboratory work, it is necessary, first of all, to determine the level of mastering the necessary practical skills and abilities achieved as a result. The article reveals the criteria and content of the methodology for the quantitative assessment of students' works in laboratory classes. Conclusions are made about the possibility of optimizing the use of quantitative assessment to improve the efficiency of laboratory work.

\section{KEYWORDS}

Assessment, implementation, preparation, criteria, restructuring, formation, principle.

\section{INTRODUCTION}

The development of our society largely depends on the initiative, knowledge, abilities, creativity of each person. In this regard, the improvement and use of laboratory facilities is of great importance, the basis of which would be high professional skill, dedication, initiative and creativity. This means that a restructuring is required as a system of value measures in the preparation, education and upbringing of students. In turn, laboratory work is also a 
school for the formation of high professional qualities of future specialists.

\section{MAIN FINDINGS AND RESULTS}

The widespread use of various laboratory works is primarily due to the fact that the process of practical training (preparation) in laboratory facilities, in principle, assumes greater efficiency than other methods. However, the effectiveness of such practical training can be said only when laboratory devices are created and applied taking into account certain didactic requirements, while it is necessary to mean not the fundamental effectiveness of practical training (practical training) on laboratory facilities.

A hands-on learning process in laboratory facilities should be considered effective if:

1. The range of practical knowledge, skills and abilities that form with the help of laboratory installations is the largest and covers those types of theoretical knowledge that are necessary for further work;

2. There is a gain in time in the formation of special practical knowledge, abilities, skills in the process of practical training in a laboratory installation;

3. If the knowledge, skills, and abilities formed in the laboratory setting have high pedagogical efficiency, namely: their level is high enough, they have accessibility, variability.

One of the methods of conducting laboratory work in the educational process is that after a short introductory speech by the teacher (or laboratory assistant), the students get to know them and begin to independently perform work on the simulator. In the course of performing the work, students systematically monitor the sequence and correctness of their actions, using the reference system contained in the description of tasks.

This method of conducting laboratory work is also possible: students study in advance a programmed task (indicates the content of the problem to be solved concerning a given topic of laboratory work, literature for preparation, control questions on theory, equipment of workplaces, safety rules, the order of work and the form reporting) and answer some of the questions contained in it one day before the laboratory classes as homework.

Each of these methods of conducting laboratory work provides a different pedagogical impact on students and has its own advantages and disadvantages. In this regard, it becomes necessary to determine a rational methodology and criteria for assessing the effectiveness of laboratory work, depending on the nature of the topic.

To assess the effectiveness of laboratory work, it is necessary, first of all, to determine the level of mastering the necessary practical skills and abilities achieved as a result of the conduct.

Below are the content of the methodology for quantitative assessment of students' works in laboratory classes.

Considering the question of the quality of testing and assessing knowledge and skills, it should be noted that the existing methods of controlling knowledge in laboratory classes, along with advantages, have certain disadvantages.

Determining the quality of assimilation of knowledge, skills and abilities is an old problem 
in pedagogical science, but the search for its solutions encounters serious difficulties associated with insufficient knowledge of the very process of the formation of human experience.

The most noticeable is the subjectivity of the assessment: the teacher, who does not have precise requirements and criteria, gives an assessment based on his personal impressions and opinions. The subjectivity of the assessment is also manifested in the fact that one and the same work estimates differ from each other by one, and sometimes by two points. A similar phenomenon is observed in exams. One person of the commission evaluates the knowledge of the material, the other the manifestation of independent thinking, the third - the possession of practical skills. However, for any type of teaching, the cornerstone in the scientific organization of pedagogical work is the unification of methods of knowledge control, which ensures a unity of approach to the teaching process.

The final stage of laboratory and practical work is the credits provided by the curriculum in the form of written reports.

Unfortunately, along with certain positive aspects, the existing method of accounting for knowledge (credits based on undifferentiated assessments) also has its own drawbacks: the main one is that knowledge is assessed superficially, this is due to the fact that despite what level he knows or answers the questions posed ( can answer with excellent, good or satisfactory), only the marks are inserted about the test or, on the contrary, not the test. For example, one in the course of the test showed a more independent and deeply knowledgeable of theory, practice, explain the scheme of the experiment, calculations, etc., and the other did not answer deeply enough, not seeing the specific focus of this work on mastering the foundations of theoretical knowledge and practical skills and abilities ... Although answering them according to the result of the work is not the same, the prize is not the same. assessed the same, it does not make it possible to first compare the availability of knowledge and the answers, analyze their work more deeply and objectively evaluate the acquired professional skills and abilities, identify the quality of knowledge, their correctness, accuracy, realize, etc. Therefore, based on the results of laboratory work, it is advisable to set off tests with a differentiated assessment, that is, by the method of quantitative assessment of knowledge.

The quantitative method of assessing the skills and skills acquired by the student, professional skills and abilities, is based on the assessment of the rating (the method of competent judges). For this, a three-point system is used. Complete fulfillment of requirements is indicated by the number- "2" partial- "1" nonfulfillment “o". “Fulfillment”, “partial fulfillment" and "' non-fulfillment have rather clear boundaries and are well defined. An important point in this is for the teacher to establish what the basic requirements will be presented during the test.

Efficiency in laboratory classes can be most assessed approximately after the duuluzim factor of knowledge, which can be divided into two groups:

First group: 
1) Theories, 2) Practices; 3) safety regulations; 4) technically competent colleague of the scheme 5) the ability to explain the scheme; 6) qualitatively perform experiments; 7) calculations.

Second group:

1) attitude to work; 2) skill; 3) determination in memory; 4) the ability to learn the current situation; 5) self-work; 6) diligence; 7) initiative and so on.

\begin{tabular}{|c|c|c|}
\hline \multirow{2}{*}{ Main requirements } & \multicolumn{2}{|c|}{ Knowledge factor group } \\
\cline { 2 - 3 } & First group & Second group \\
\hline 1 & 2 & 0 \\
\hline 2 & 1 & 1 \\
\hline 3 & 0 & 0 \\
\hline 4 & 1 & 1 \\
\hline 5 & 1 & 0 \\
\hline 6 & 2 & 2 \\
\hline 7 & 0 & 2 \\
\hline Points & 7 & 6 \\
\hline
\end{tabular}

This table is filled in immediately when checking knowledge.

In this case, the overall level of prioritization of laboratory navigation and skills is $B=-28^{13,100 \%=}$ $47 \%$.

If these requirements are met $90 \%$ higher, then they correspond to a high level, excellent, if these requirements are met in the range of 70 $89 \%$, they can be considered optimal (good); when performed at 50-69\%, it can be considered average (satisfactory).

The name of such a plate what recommendations (advice) can be given to the teacher. These conclusions and recommendations clearly follow from which requirements for a modern occupation of concrete implemented in practice are the weakest, and which are not at all implemented (score) "o". Noting the positive aspects (full) fulfillment of the requirements of the estimated scores " 2 ", the teacher indicates that he needs to improve specifically in the first order, which is rated "o".
For sure, such a division may not be enough; it can be changed (races) depending on the needs.

If in the test scheme for the laboratory work I am considered in two groups of 14 remaining requirements, then their full fulfillment can be maximum 28 points (points), which will correspond to $100 \%$ (table 1 ).
Here you need to pay attention to the safety rules (s.r.), as well as the attitude to work (p. 1), and so force. Afterwards, advice is given to improve the fulfillment of those requirements that are partially implemented in the classroom (rated “1”).

\section{CONSCLUSION}

In conclusion, we note that based on the abovementioned requirements, the teacher can loudly, objectively and competently check and evaluate the understanding of practical skills in laboratory classes.

\section{REFERENCES}

1. N. Muslimov (2007). Theoretical and Methodological Bases of Professional Formation of a Teacher of Vocational Education: Doctor of Pedagogical Sciences, - Tashkent.

2. Kh. Togaev, U.K. Tolipov (1993) Pedagogical Foundations Perfecting a 
Creative Personality. Russian Academy of Education. Institute for Learning Tools. Methodical Manual, - Moscow.

3. Kh Togaev (2003). Qualities of Personnel Training: Problems and Solutions. Tashkent: "UFZhBNT".

4. Yu. N. Chestnykh (1991). Open The Person. - Moscow: "Enlightenment".

5. Farfieva K. A. Social Media as a factor in formation of scientific thinking in youth. European Journal of Research and Reflection in Educational Sciences. Vol. 8 No. 10, 2020. - Pp. 52-56. 